\title{
Effects of Live and Heat-Inactivated $E$. coli Strains and Their Supernatants on Immune Regulation in HT-29 Cells
}

\author{
Christian Zimmermann ${ }^{1}$, Marius Schild ${ }^{1}$, Clemens Kunz ${ }^{1}$, Kurt Zimmermann² and Sabine Kuntz ${ }^{1}$ \\ ${ }^{1}$ Institute of Nutritional Science, Justus Liebig University Giessen, Wilhelmstrasse 20, D-35392 Giessen, Germany \\ ${ }^{2}$ SymbioPharm GmbH, Auf den Lueppen 10, D-35745 Herborn, Germany
}

Received: 02 February 2018; accepted: 16 March 2018

\begin{abstract}
Probiotics are considered to have a beneficial impact on humans, but in some cases, administration of live microorganisms might be risky. In the present study, immunomodulatory effects of different Escherichia coli strains and their supernatants were examined under different inflammatory conditions with living and heat-inactivated strains. HT-29 cells were incubated with $E$. coli strains (S2-G1, S2-G3, S2-G4 and S2-G8) and their supernatants with or without stimulation with tumor necrosis factor alpha (TNF- $\alpha$ ) or interleukin (IL)-1 $\beta$. Quantification of IL-8 secretion and gene expression was performed by enzyme-linked immunosorbent assay (ELISA) and real-time polymerase chain reaction (PCR). IL-8 secretion by TNF- $\alpha$ - and IL- $1 \beta$-stimulated cells was attenuated by all four live strains. In contrast, heat inactivation resulted in an elevated IL-8 expression and secretion in unstimulated cells and did not maintain the anti-inflammatory effect of live bacteria in cytokine-stimulated cells. The supernatant of the live S2-G3 led to an elevated IL- 8 secretion in unstimulated and IL- $1 \beta$-stimulated cells but not in TNF- $\alpha$-stimulated cells. Live bacteria of all strains might induce an immunosuppressive effect after stimulation of HT-29 cells, whereas heat inactivation and the supernatant seem to induce an elevated immune response. These findings might have an impact depending on the indication and purpose of administration.
\end{abstract}

Keywords: probiotics, E. coli, heat-inactivated, supernatant, TNF- $\alpha$, IL-1 $\beta$, IL-8, intestinal inflammation, in vitro

\section{Introduction}

According to the definition of the World Health Organization and the Food and Agricultural Organization of the United Nations (WHO/FAO), probiotics are live microorganisms which confer health benefits to hosts when administered in adequate amounts $[1,2]$. In general, beneficial effects attributed to probiotics include improvement of intestinal health, decreased hypertension, reduced serum cholesterol levels, and prevention of cancer [3, 4]. However, generalizations concerning the potential health benefits of probiotics should not be made as probiotic effects tend to be strain-specific [3]. Furthermore, different from the general WHO definition, dead bacteria and bacterial molecular components may exhibit probiotic properties $[2,5,6]$.

Most of these effects are considered to be due to their interactions with the intestinal microbiota and direct interactions with the host immune system [2]. Whether probiotics might have an impact on inflammatory bowel disease (IBD) is still under debate $[7,8]$. IBD comprises variable courses of disease with a heterogeneous group of patients [9]. Tumor necrosis factor alpha (TNF- $\alpha)$ is recognized as one of the most important cytokines in acute inflammation phase and therefore identified as a major target for therapies with monoclonal antibodies $[9,10]$. Members of the interleukin (IL)-1 family, like IL-1 $\beta$, are also found to be involved during the acute phase response. According to in vivo experiments, blockade of IL-1 family members could be relevant for the therapy of IBD $[11,12]$.

As a matter of fact, it is postulated that Escherichia coli Nissle 1917 was as effective as the anti-inflammatory substance mesalazine in preventing relapses in the case of ulcerative colitis [13]. However, there are concerns that in

\footnotetext{
* Correspondence: E-mail: Christian.A.Zimmermann@ernaehrung.uni-giessen.de; Phone: +49-(0)641-99-39056; Fax: +49-(0)641-99-39049
}

immunocompromised patients, who are predisposed to infections, live probiotics may cause adverse effects. For example, bacteremia or endocarditis caused by Lactobacillus has been documented in a few case reports [6, 14-16]. Furthermore, Lactobacillus has also been associated with increased mortality in predicted acute pancreatitis [17]. In this context, the application of inactivated probiotics may offer an opportunity to exert a similar probiotic effect without adverse side effects. While bacteria-bacteria interactions and competition for nutrients are restricted to live probiotics, the crosstalk with host epithelial cells and, therefore, an immunological response for which bacteria not necessarily need to be alive might also be evoked by bacterial components [2, 18].

Remarkably, recent research has shown that inactivated microorganisms potentially have an impact on inflammatory immune regulation as well. It has been demonstrated that certain heatinactivated bacteria induced anti-inflammatory reactions in rat colonic tissue [19], whereas other studies reported an elevated inflammatory activity in a pretreated cell culture model [20]. In vitro experiments with heat-inactivated Bifidobacterium breve and Bifidobacterium bifidum strains have shown no impact on the secretion of IL- 8 in TNF- $\alpha$-stimulated HT-29 cells. In contrast, the supernatant and isolated DNA of both strains inhibited the secretion of IL-8 [21]. Zhang et al. [22] reported a decreased secretion of IL- 8 by TNF- $\alpha$-stimulated Caco- 2 cells incubated with live and heat-inactivated Lactobacillus rhamnosus GG (LGG). However, high doses of live LGG increased the secretion of IL-8 in contrast to heat-inactivated LGG. On the contrary, Hwan et al. [23] have shown reduced IL-8 secretion by LGG in IL-1 $\beta$-stimulated Caco-2 cells, which was abolished by heat inactivation of the bacteria. In addition to heat, inactivation by drying, ultrasound, or irradiation was reported to affect the immunomodulatory properties of different bacteria. For example, IL-8 secretion of HT-29 cells was upregulated by ultrasound inactivation of E. coli Nissle 1917 [24]. In contrast,

This is an open-access article distributed under the terms of the Creative Commons Attribution-NonCommercial 4.0 International License (https://creativecommons.org/licenses/by-nc/4.0/), which permits unrestricted use, distribution, and reproduction in any medium for non-commercial purposes, provided the original author and source are credited, a link to the CC License is provided, and changes - if any - are indicated. 
different irradiated Lactobacillus or Bifidobacterium strains attenuated IL-8 secretion by Caco-2 cells [25].

Besides lactic acid bacteria and Bifidobacteria, some E. coli strains have also shown beneficial effects on human health [26-29]. In particular, E. coli Nissle 1917 commercially distributed as Mutaflor ${ }^{\circledR}$ is a prominent exponent, and also other probiotic E. coli products like Symbioflor ${ }^{\circledR} 2$ are reported to have a beneficial impact (reviewed in Wassenaar's work [30]). Alongside the discussion whether probiotics have to be alive or can be inactivated [31], recent research has also focused on using supernatants of different live and/or inactivated bacterial strains defined as probiotic as immunomodulatory agents $[23,32,33]$. For example, Ren et al. [33] reported an inhibition of IL-8 secretion in Caco-2 cells after immune-stimulating treatment with TNF- $\alpha$. In our experiments, we used four E. coli strains of the probiotic product Symbioflor ${ }^{\circledR} 2$, which is used in the treatment of irritable bowel syndrome. In particular, the strains E. coli S2-G1, S2-G3, S2-G4, and S2-G8 were applied to examine their effects on the expression and secretion of IL-8 in human colorectal adenocarcinoma cell line HT-29. To investigate potential immunomodulatory effects that depend on the type of treatment, all four strains were applied either alive or heat-inactivated. As both secreted substances of live bacteria and bacterial fragments have shown effects on the immunological status [21, 24, 33, 34], the supernatants of live and heat-inactivated bacteria were investigated. Due to their proinflammatory activity, TNF- $\alpha$ and IL-1 $\beta$ play an important role in the pathogenesis of IBD. To mimic the process of cytokinestimulated inflammation in IBD [12], HT-29 cells were also stimulated with either IL- $1 \beta$ or TNF- $\alpha$ after bacteria administration. Subsequently, the impact of an acute inflammation on IL-8 production after treatment with probiotic bacteria and their supernatants was examined.

The primary objective of this study was to examine whether bacterial viability is a factor of the probiotic immunomodulatory effect. Therefore, live or heat-inactivated potentially probiotic E. coli strains (S2-G1, S2-G3, S2-G4, and S2-G8) and their corresponding supernatants were exposed to non-stimulated or TNF- $\alpha$ - or IL- $1 \beta$-stimulated HT- 29 cells as a model of intestinal inflammation. IL-8 expression and secretion were determined as markers of immune-relevant effects.

\section{Materials and Methods}

Cell Culture Conditions. The human colon carcinoma cell line HT-29 was obtained from LGC (LGC standard GmbH, Wesel, Germany). HT-29 cells were routinely cultured in RPMI 1640 supplemented with $10 \%$ heat-inactivated fetal calf serum (FCS) and $2 \mathrm{mmol} / \mathrm{L}$ glutamine in $75 \mathrm{~cm}^{2}$ flasks (all Thermo Fisher Scientific, Darmstadt, Germany) in an incubator (Heraeus, Hanau, Germany) at $37{ }^{\circ} \mathrm{C}, 95 \%$ humidity and $5 \% \mathrm{CO}_{2}$. For the experiment, $5 \times 10^{5}$ cells with passage 4-20 were seeded in 24-well tissue culture plates (Greiner Bio-One, Frickenhausen, Germany) and cultivated for 2 days resulting in a confluent cell layer.

Bacteria Culture Conditions. The bacterial species used in this study are E. coli S2-G1 (DSM 16441), S2-G3 (DSM 16443), S2-G4 (DSM 16444), and S2-G8 (DSM 16448). All bacterial strains were provided by SymbioPharm GmbH (Herborn, Germany). The strains are part of the probiotic Symbioflor ${ }^{\circledR} 2$ (DSM 17252) drug. For incubation experiments, $20 \mathrm{~mL} \mathrm{LB}$ Broth (Miller) medium (Sigma Aldrich, Munich, Germany) were inoculated with $500 \mu \mathrm{L}$ of the appropriate E. coli overnight culture and incubated at $37{ }^{\circ} \mathrm{C}$ with gentle shaking (Certomat; B. Braun, Melsungen, Germany) under aerobic conditions until it reached the exponential phase of growth $\left(\mathrm{OD}_{600}=0.7-1.0\right)$. The number of bacteria was calculated by multiplying $\mathrm{OD}_{600}$ by $8 \times 10^{8}$. In the exponential growing phase, $10^{8}$ bacteria were collected in $250 \mu \mathrm{L}$ bacterial growth medium. For heat inactivation, bacterial suspension was heated for $21 \mathrm{~min}$ at $121^{\circ} \mathrm{C}$ and stored at $-20{ }^{\circ} \mathrm{C}$ until the next day. In the experiments performed with the supernatant, live or heat-inactivated bacteria were centrifuged at $2500 \mathrm{~g}$ for $10 \mathrm{~min}$ (Hettich, Tuttlingen, Germany). The resulting supernatant was filtrated with $0.2 \mu \mathrm{m}$ syringe filters (Thermo Fisher Scientific).

Incubation of HT-29 Cells with Live or Heat-Inactivated Bacteria/Bacterial Supernatant. After attaining confluence, the culture medium of the HT-29 cell monolayers was removed. For the incubation of HT-29 cells, $250 \mu \mathrm{L}$ of the bacterial suspension or supernatant was mixed with $250 \mu \mathrm{L}$ of HT-29 culture medium. Each cavity of the HT-29 24-well plate was incubated with $500 \mu \mathrm{L}$ of the particular suspension for $4 \mathrm{~h}$ at $37{ }^{\circ} \mathrm{C}, 95 \%$ humidity and $5 \% \mathrm{CO}_{2}$. After $1 \mathrm{~h}$ of incubation, $50 \mu \mathrm{L}$ of HT-29 culture medium with or without $\mathrm{IL}-1 \beta$ or TNF- $\alpha$ (final concentration: $10 \mathrm{ng} / \mathrm{mL}$ ) was added. At the end of incubation, HT-29 supernatants were collected and stored at $-20{ }^{\circ} \mathrm{C}$ until performing enzyme-linked immunosorbent assay (ELISA). Cells were washed with HT-29 cell culture medium and lysed with TRI Reagent (Sigma-Aldrich). Lysed cells were collected and stored at $-80{ }^{\circ} \mathrm{C}$ until real-time time polymerase chain reaction (PCR) was performed.

IL-8 Protein Analysis (ELISA). Cell culture supernatants were analyzed for IL-8 concentrations using the RayBio Human IL-8 ELISA Kit (RayBiotech, Norcross, GA, USA) with a detection limit of $1 \mathrm{pg} / \mathrm{mL}$ and a Digiscan Reader (Asya Hitech $\mathrm{GmbH}$, Eugendorf, Austria) according to the manufacturer's instructions. Calculation of IL-8 concentration was conducted using GraphPad Prism 7.01 (GraphPad Software, Inc., La Jolla, CA, USA). Increasing or decreasing IL-8 concentrations ( $\mathrm{pg} / \mathrm{mL})$ were compared with the corresponding negative control (each $n=3$, done in duplicate).

IL-8 mRNA Analysis (Real-Time PCR). The lysed cells from the incubation experiment were used for isolation of mRNA, as described previously [35]. In brief, RNA was isolated by using ice cold chloroform (Merck, Darmstadt, Germany) and subsequent centrifugation (Hettich, Tuttingen, Germany). RNA precipitation was done by using isopropanol (Carl Roth, Karlsruhe, Germany). Thereafter, precipitated RNA was washed with ethanol (Merck, Darmstadt, Germany) and resuspended in water (Life Technologies) and ribonuclease (RNase) inhibitor (Fermentas, St. Leon-Rot, Germany). Purity and concentration of RNA were analyzed using a NanoDrop 1000 (Thermo Fisher Scientific, Darmstadt, Germany) and calculated with Microsoft Excel (Microsoft, Redmond, WA, USA). Possible DNA contaminations were removed by deoxyribonuclease (DNase) I digestion (Sigma-Aldrich). Transcription of RNA in complementary DNA (cDNA) was done using Oligo-dT-primers, dNTPs, and reverse transcriptase from Promega (Mannheim, Germany). Realtime TaqMan ${ }^{\mathrm{TM}}$ PCR was performed using qPCR MasterMix Plus (Eurogentec, Seraing, Belgium) and primers and probes (SigmaAldrich) listed in Table 1. The results are expressed as $2^{\text {-ddct }}$.

Statistical Analysis. Individual experiments were statistically analyzed using one-factorial analysis of variance (ANOVA) for independent samples. For multiple testing, Dunnett's multiple comparison post-hoc tests were conducted to compare the four strains with the control. The results are presented as mean \pm standard deviation (SD). For all analyses, a $p$-value $<0.05$ was considered to be significant. GraphPad Prism 7.01 (GraphPad Software, La Jolla, USA) was used for statistical analysis.

Ethics. This in vitro study was performed in accordance to the good laboratory practice (GLP).

\section{Results}

Effect of Live E. coli Strains on IL-8 mRNA-Expression and Secretion by HT-29. To examine the effect of four specific 
Table 1. Primer and probes (Sigma-Aldrich, Munich, Germany)

\begin{tabular}{|c|c|c|c|c|}
\hline Gene & & Sequence & & $\mathrm{bp}$ \\
\hline$\beta$-Actin FP & $5^{\prime}$ & ACCCACACTGTGCCCATCTAC & $3^{\prime}$ & 21 \\
\hline$\beta$-Actin RP & $5^{\prime}$ & TCGGTGAGGATCTTCATGAGGTA & $3^{\prime}$ & 23 \\
\hline IL-8 FP & $5^{\prime}$ & AGCTGGCCGTGGCTCTCT & $3^{\prime}$ & 18 \\
\hline IL-8 RP & $5^{\prime}$ & TTTAGCACTCCTTGGCAAAACTG & $3^{\prime}$ & 23 \\
\hline$\beta$-Actin probe & $5^{\prime}$ & 6-FAM-ATGCCCTCCCCCATGCCATCC-TAMRA & $3^{\prime}$ & 21 \\
\hline IL-8 probe & $5^{\prime}$ & 6-FAM-CAGCCTTCCTGATTTCTGCAGCTCTGTG-TAMRA & $3^{\prime}$ & 28 \\
\hline
\end{tabular}

E. coli strains on the inflammatory response of HT-29 cells, the expression and secretion of IL-8 were measured by real-time PCR and ELISA, respectively, under unstimulated and stimulated conditions. HT-29 cells incubated with the E. coli strains S2-G1, S2-G3, or S2-G8 did not show any significant effect on IL-8 secretion under unstimulated conditions. However, strain S2-G4 reduced the secretion of IL-8 measured $4 \mathrm{~h}$ after incubation (Figure 1A). Considering the expression of IL-8 in this approach, strain S2-G3 showed a significant increase of IL-8 mRNA expression, whereas the other strains did not (Figure 1D). An additional stimulation with TNF- $\alpha$ or IL-1 $\beta$ increased the IL- 8 secretion by HT-29 cells. Previous incubation with all tested strains prevented the cytokine-stimulated secretion of IL-8, thus resulting in an IL-8 level similar to that of unstimulated cells (Figure 1B, C). The significant decrease of IL-8 was also observed for all strains at the mRNA-expression level, except for strain S2-G3 for which no effect was found in IL-1 $\beta$-stimulated cells (Figure 1E, F).

Effects of the Supernatants of Live E. coli Strains on IL8 mRNA-Expression and Secretion by HT-29. To investigate the effect of metabolites secreted by the bacteria, the supernatants of the E. coli strains were incubated with HT-29 cells. In contrast
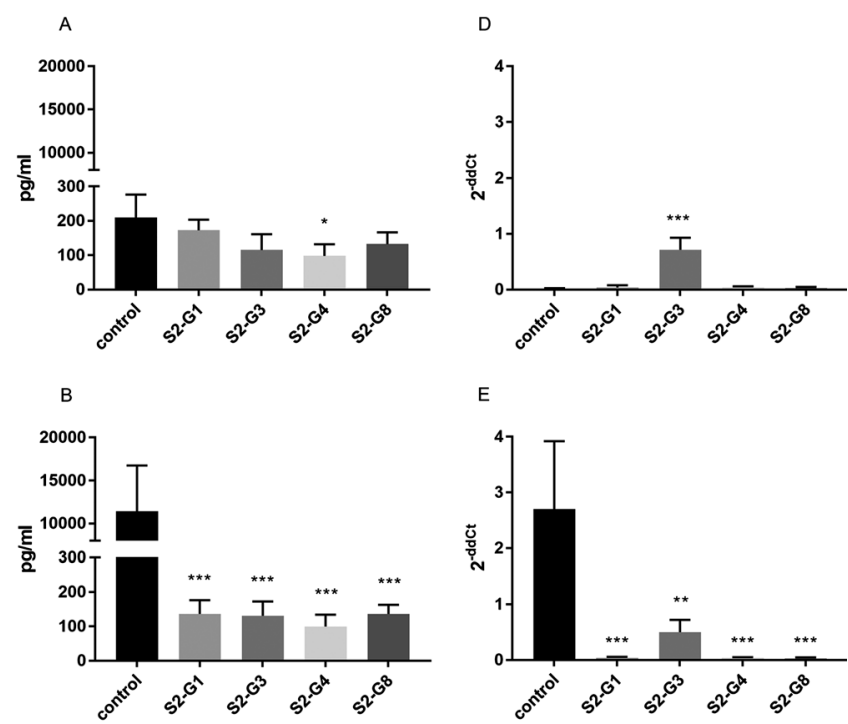

E
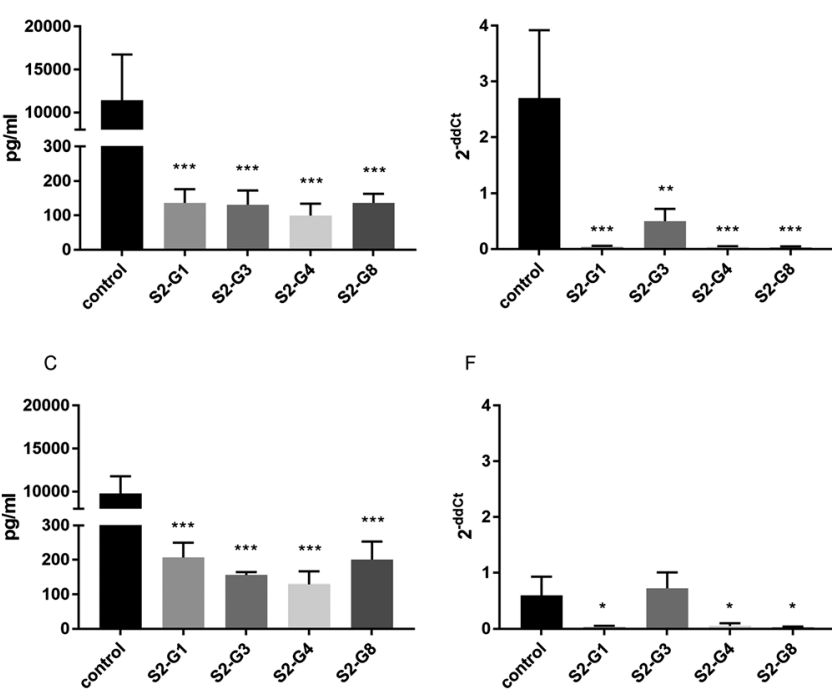

Figure 1. Quantification of IL-8 secretion (A-C) and mRNA expression (D-F) by HT-29 cells incubated with different $E$. coli strains. IL-8 secretion and expression of unstimulated cells (A and D), cells stimulated with TNF- $\alpha$ (B and E), and cells stimulated with IL-1 $\beta$ (C and F) are shown. ${ }^{*} p<0.05,{ }^{*} p<0.01$, and ${ }^{* * *} p<0.001$ show statistical significance in comparison with the control. Data are given as means and standard deviation $(n=3)$ to the other strains, S2-G3 increased the mRNA expression and secretion of IL-8 during $4 \mathrm{~h}$ of incubation (Figure 2A, D). Additional incubation with cytokines had no significant influence on the increased IL-8 secretion except for strain S2-G3, which increased the IL- 8 secretion in IL- $1 \beta$-stimulated cells (Figure 2B, C). For IL-8 expression, no effect of the bacteria was observed in comparison with the control (Figure 2E, F).

Effect of Heat-Inactivated $E$. coli Strains and their Supernatants on IL-8 mRNA-Expression and Secretion by HT-29. The treatment of the E. coli strains at $121{ }^{\circ} \mathrm{C}$ for $21 \mathrm{~min}$ significantly increased the expression and secretion of IL-8. However, this was not the case with S2-G3, which did not induce a significant elevation of IL-8 secretion (Figure 3A, D). In contrast, there was no significant difference between the IL-8 secretion of cytokine-stimulated HT-29 cells and cells additionally incubated with heat-treated E. coli strains (Figure 3B, C). However, heat-treated S2-G1, S2-G4, and S2-G8 showed a significant elevation of IL-8 mRNA expression (Figure 3F).

Similar effects were observed by incubation of HT-29 cells with supernatants of heat-treated bacteria. Although the supernatant of heat-treated S2-G1, S2-G3, and S2-G8 stimulated IL-8 expression
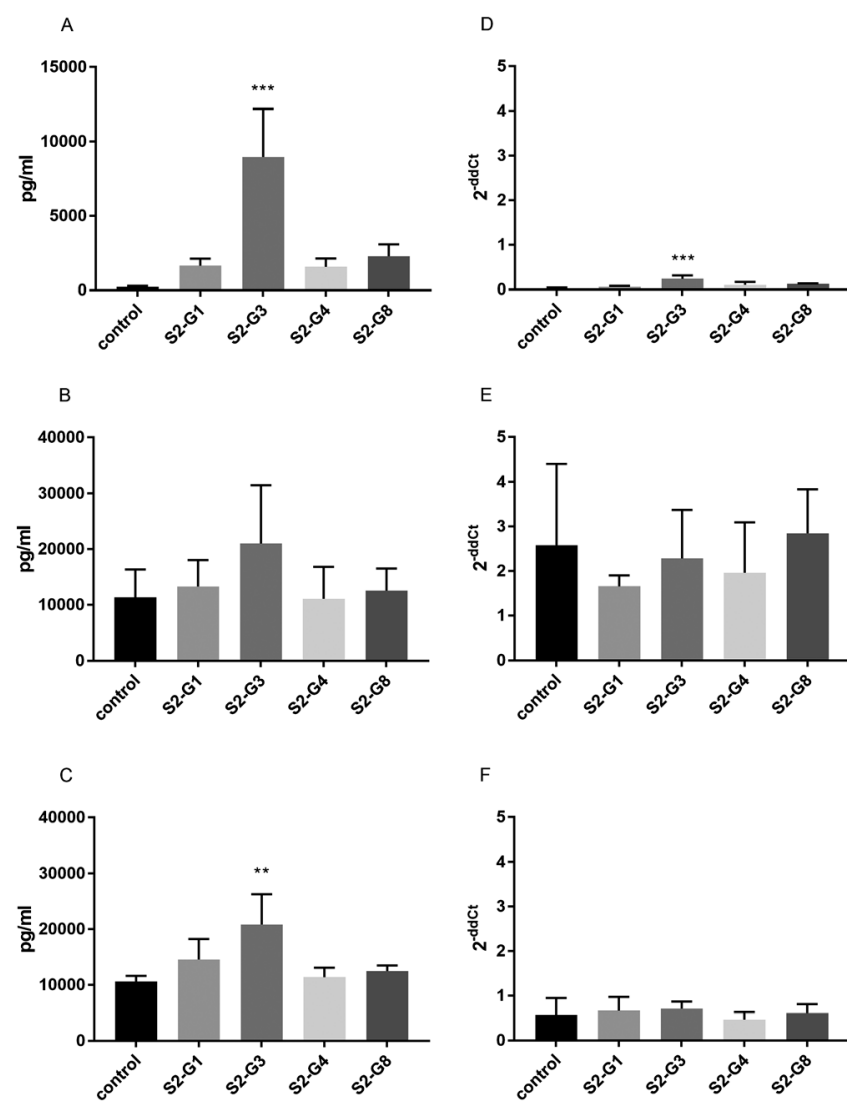

Figure 2. Quantification of IL-8 secretion (A-C) and mRNA expression (D-F) by HT-29 cells incubated with the supernatants of different $E$. coli strains. IL-8 secretion and expression of unstimulated cells (A and D), cells stimulated with TNF- $\alpha$ (B and E), and cells stimulated with IL-1 $\beta\left(\mathrm{C}\right.$ and $\mathrm{F}$ ) are shown. ${ }^{* *} p<0.01$ and ${ }^{* * *} p<0.001$ show statistical significance in comparison with the control. Data are given as means and standard deviation $(n=3)$ 


$$
\text { A }
$$
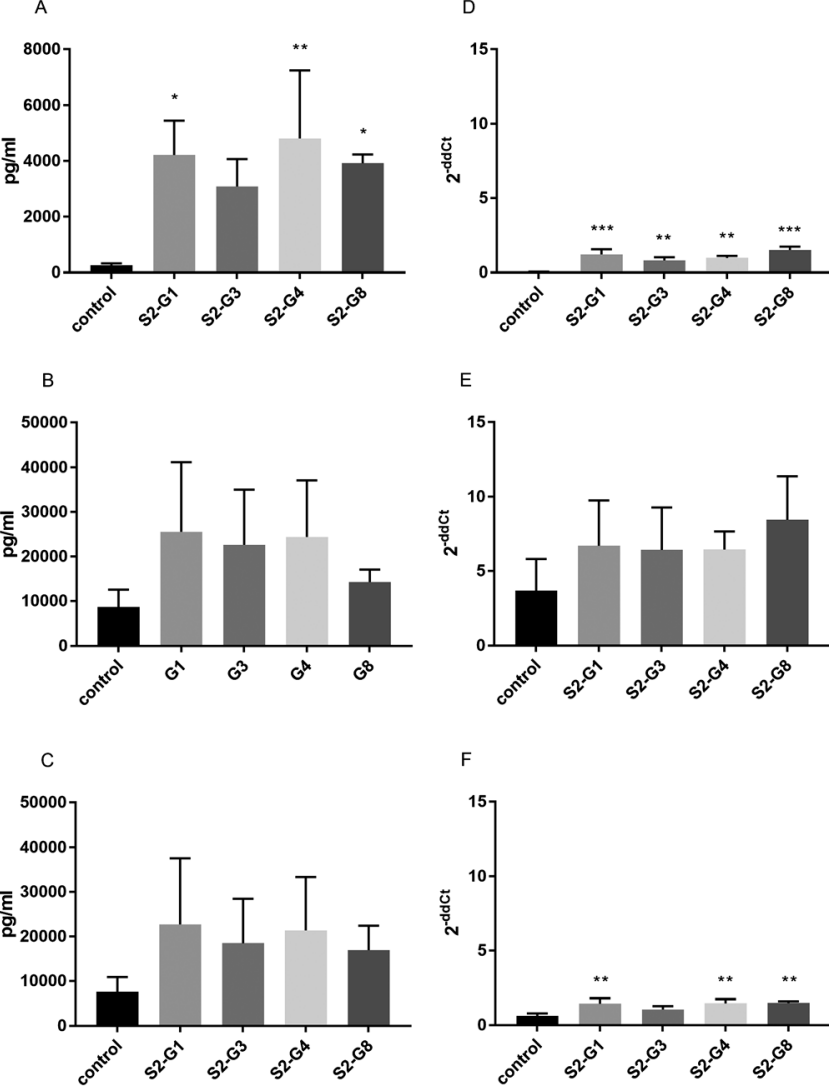

Figure 3. Quantification of IL-8 secretion (A-C) and mRNA expression (D-F) by HT-29 cells incubated with different heat-inactivated $E$. coli strains. IL-8 secretion and expression of unstimulated cells (A and D), cells stimulated with TNF- $\alpha$ (B and E), and cells stimulated with IL-1 $\beta$ (C and F) are shown. ${ }^{*} p<0.05,{ }^{*} p<<0.01$, and ${ }^{* * *} p<0.001$ show statistical significance in comparison with the control. Data are given as means and standard deviation $(n=3)$

and secretion in unstimulated cells (Figure 4A, D), no effect was observed in cytokine-stimulated cells (Figure 4B, C and E, F).

\section{Discussion}

Intestinal epithelial cells play a critical role as a structural and functional barrier against pathogens. In this context, mucosal tolerance against luminal bacteria is important to prevent an overreaction of the immune system. To maintain homeostasis, intestinal epithelial cells produce antimicrobial peptides and factors promoting the differentiation of anti-inflammatory immune cells [36]. It was shown that, in response to several pathogenic bacteria, the host's immune system produces the chemokine IL-8, leading to recruitment of leukocytes [37, 38]. As a disease associated with a lack of intestinal homeostasis, IBD is accompanied by an elevated production of IL- 8 , and therapies affecting IL-8 may modify inflammation in IBD [39]. Until today, the influence of probiotic bacteria on IBD has not been cleared, but several studies have shown the impact of probiotic bacteria by attenuating IL-8 secretion in cytokinestimulated cells, thus potentially contributing to the maintenance of intestinal homeostasis [21, 23, 25, 32, 33, 40, 41].

In the present study, we investigated the effects of four $E$. coli strains of the probiotic product Symbioflor ${ }^{\circledR} 2$, which is recommended for the treatment of irritable bowel syndrome [26, 42]. The genome sequences of these $E$. coli strains have recently been characterized [28]. However, the immunologic effects of these bacteria on enterocytes have not been examined yet. Therefore, we investigated the effect of these $E$. coli strains on the IL-8 expression and secretion in the colonic epithelial cell line HT-29.
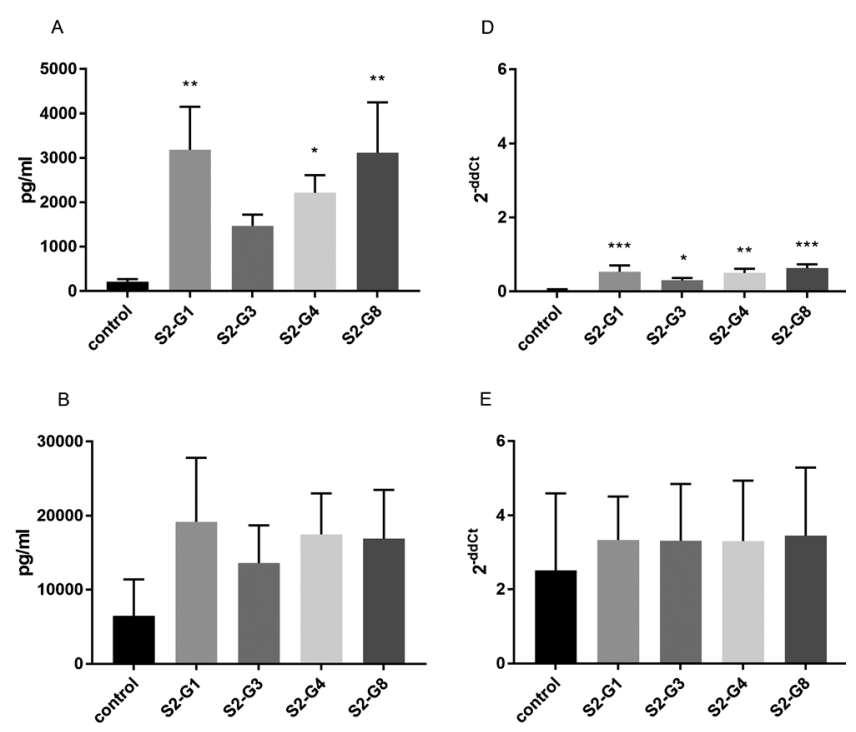

E
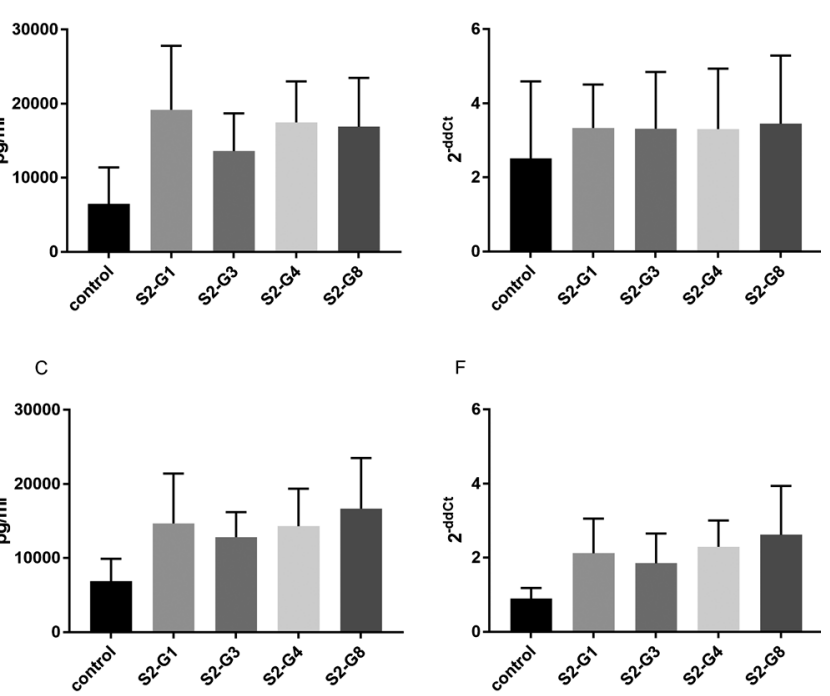

Figure 4. Quantification of IL-8 secretion (A-C) and mRNA expression (D-F) by HT-29 cells incubated with the supernatants of different heat-inactivated E. coli strains. IL-8 secretion and expression of unstimulated cells (A and D), cells stimulated with TNF- $\alpha$ (B and E) and cells stimulated with $\mathrm{IL}-1 \beta(\mathrm{C}$ and $\mathrm{F})$ are shown. ${ }^{*} p<0.05, * * p<$ 0.01 , and $* * * p<0.001$ show statistical significance in comparison with the control. Data are given as means and standard deviation $(n=3)$

We demonstrated that the secretion of IL- 8 by TNF- $\alpha$ - and IL-1 $\beta$-stimulated HT-29 cells was inhibited by pretreatment with all tested $E$. coli strains and subsequently reduced to a basal level. However, only strain S2-G4 showed significant inhibition of IL-8 secretion in unstimulated cells, suggesting anti-inflammatory characteristics of these E. coli strains in inflammatory but only limited effects in basal conditions. The shown effects are in agreement with the results of other working groups using different strains of Bifidobacteria or Lactobacillus, in which the IL-8 secretion of cytokine-stimulated but not of unstimulated intestinal cell lines was inhibited [23, 33, 40, 41]. In accordance with the secretion data, mRNA expression of IL8 in cytokine-stimulated but not in unstimulated cells was inhibited by the tested E. coli strains. However, strain S2-G3 did not show any effect in IL- $1 \beta$-stimulated cells and a significant upregulation of IL- 8 mRNA expression without the addition of cytokines. Recently, the genomes of the bacterial components of Symbioflor ${ }^{\circledR} 2$ have been sequenced, showing strain S2-G3 to be most dissimilar to the other strains. Two genome islands were identified to be unique for S2-G3, containing transposases and other remnants of mobile DNA elements, as well as remnants of prophage. A possible difference between IL-8 production induced by S2-G3 and that induced by other tested strains could be explained by the differences in bacterial surface molecules, like type 3 fimbriae identified in strain S2-G3 but not in S2-G1, -G4, or -G8 [28]. Fimbriae on bacterial surfaces are important in mediating the adhesion process to host cells [43], supposing that type 3 fimbriae of E. coli S2-G3 increased the interaction with HT-29 cells, resulting in inflammatory stimulation. According to these strain specific results for 
E. coli S2-G3, Otte et al. [32] observed an increase of IL-8 secretion by HT-29 and T84 cells after 6 and $12 \mathrm{~h}$ of coincubation with $E$. coli Nissle 1917 without further cytokine stimulation.

Although the WHO/FAO definition of probiotics refers to live microorganisms, a potential probiotic effect of non-viable bacteria is proposed $[2,18,31]$. Besides that, there are concerns about possible side effects of the administration of live probiotic bacteria, including a higher risk for immunocompromised people or young children [14-17, 44]. Hence, the administration of inactivated bacteria or bacterial supernatants could be an alternative treatment, reducing the potential risks but maintaining the positive effects. We have shown that, in contrast to live E. coli, the supernatant of strain S2-G3 induced an increase of IL- 8 secretion and mRNA expression in unstimulated cells, as well as an increase of IL- 8 secretion in IL-1 $\beta$-stimulated cells, whereas the supernatants of all other strains had no significant effect on unstimulated or stimulated cells. This revealed a pro-inflammatory capability of soluble substances secreted by E. coli S2-G3, which seem to have no effect on IL-8 secretion, in combination with the live bacteria at this point of time. In line with our results, Zargar et al. [45] have shown that the secreted products of the nonpathogenic E. coli strains BL21 and W3110 activate the transcription of cytokines including IL-8 involved in the induction of neutrophils. However, studies with supernatants of different strains of Lactobacillus and Bifidobacteria have shown inhibitory activity against IL- $1 \beta$ - and TNF- $\alpha$-stimulated inflammation $[23,46]$. Imaoka et al. [21] concluded that not a single component can be made responsible for the anti-inflammatory effects, but possibly the glycolipids, glycans, or acetic acid present in bacterial supernatants $[21,46]$. Different cell wall component composition [18] and their release, the concentration of fermentation products [47], and other molecules [18] in the supernatant and their interaction with pattern recognition receptors can be seen as possible explanations for the varying immunomodulatory effects.

In contrast to live bacteria, heat inactivation of the $E$. coli strains induced a pro-inflammatory effect on HT-29 cells not stimulated with cytokines. In addition, the anti-inflammatory effect of all live E. coli strains was not maintained when heatinactivated $E$. coli were used. This was also reported for different strains of heat-inactivated Lactobacillus and Bifidobacteria leading to an increased IL- 8 secretion by TNF- $\alpha$-stimulated intestinal epithelial cells [33]. In regard to a study from Wong and Ustunol [25], not only the differences between strains but also the mode of inactivation had an impact on the IL-8 production.

In addition, we observed that the supernatants of heatinactivated $E$. coli showed a similar effect to the heat-inactivated bacteria suspension, supposing that soluble components released by inactivated bacteria might also be responsible for the inflammatory impact. As already mentioned, especially after heat inactivation, bacterial cell components might be found in the supernatants and therefore account for the immunomodulatory effects and counteract as potential pro-inflammatory detergent. Therefore, the analysis of the emerging cell debris after heat inactivation is important to determine the immunomodulatory components. However, a detailed investigation of the supernatants was beyond the scope of the presented research but should be considered as an important factor in further research.

To summarize, our data show for the first time that the tested $E$. coli strains are able to inhibit expression and secretion of IL-8 in cytokine-stimulated enterocytes and that heat inactivation of the strains abolish this effect. Experiments with the bacterial supernatants revealed a pro-inflammatory potential of substances secreted by strain S2-G3, which distinguishes it from the other strains.
Hence, the tested heat-inactivated $E$. coli strains and the supernatants have different properties than the live bacteria, and therefore they are not interchangeable, but could be used in different applications.

Generally, when describing the immunological effects of specific bacteria, it is important to differentiate if live bacteria, inactivated bacteria, or even supernatants of bacteria were used. In addition, the mode of inactivation is supposed to affect the immunological response. These circumstances make it difficult to draw ambitious and generalized conclusions. Our findings might be of importance for the application of treated or untreated probiotic strains in inflammatory diseases. While, in the remission of IBD, an anti-inflammatory effect is desirable, as can be observed for the live E. coli strains in the present study, there might also be applications benefiting from immune-stimulating properties, which therefore justifies heat inactivation or the usage of supernatants under certain conditions, e.g., in irritable bowel syndrome [48].

\section{Conclusions}

Nowadays, the intake of probiotics plays a role in the therapeutic treatment of several intestinal diseases and, for the broad public, even more importantly, the application via commercially available products. However, there are differences not only between various strains, for example, Lactobacillus and E. coli, but also with respect to the way of application and treatment (e.g., inactivation by heating at different temperatures and varying duration). Our results indicate that, in addition to the differences between bacterial strains, heat inactivation and the usage of supernatants instead of the bacteria have a different immunomodulatory impact. While there are good reasons to refrain from using live bacteria, especially in immune-deficient patients, it should be considered that the proposed effects of inactivated bacteria or bacterial products can vary. Hereby, not only anti-inflammatory but also immune-stimulating functions should be in the scope of therapeutic approaches to treat various inflammatory diseases.

\section{Funding Sources}

The study was supported, in part, by SymbioPharm GmbH.

\section{Author Contributions}

S.K., C.K., and C.Z. conceived and designed the experiments; C.Z. and M.S. performed the experiments; C.Z. and M.S. analyzed the data; K.Z. contributed the bacterial strains; C.Z. and M.S. wrote the article. S.K., C.K., and K.Z. critically reviewed the article. All authors approved the final version of the article.

\section{Conflict of Interest}

K.Z. is a staff member of SymbioPharm GmbH. SymbioPharm GmbH had no role in the design of the study, analyses, or interpretation of data, in the writing of the article, and in the decision to publish the results. The other authors declare no conflict of interest.

Acknowledgments. The authors would like to thank Ms. Katrin Koslowski for her excellent technical assistance. Bacterial strains were provided by SymbioPharm GmbH, Herborn, Germany. Materials for experiments have also been partly provided by SymbioPharm GmbH. 


\section{References}

1. Hill C, Guarner F, Reid G, Gibson GR, Merenstein DJ, et al. Expert consensus document. The International Scientific Association for Probiotics and Prebiotics consensus statement on the scope and appropriate use of the term probiotic. Nat Rev Gastroenterol Hepatol. 2014;11:506-14. Available from: http://www.nature.com/nrgastro/journal/v11/n8/pdf/nrgastro.2014.66.pdf. Accessed 18 August 2016.

2. Adams CA. The probiotic paradox: live and dead cells are biological response modifiers. Nutr Res Rev. 2010;23:37-46.

3. Kechagia M, Basoulis D, Konstantopoulou S, Dimitriadi D, Gyftopoulou K, et al. Health benefits of probiotics: a review. ISRN Nutr. 2013:481651.

4. Shi LH, Balakrishnan K, Thiagarajah K, Mohd Ismail NI, Yin OS. Beneficial properties of probiotics. Trop Life Sci Res. 2016;27:73-90.

5. Giahi L, Aumueller E, Elmadfa I, Haslberger AG. Regulation of TLR4, p38 MAPkinase, IKB and miRNAs by inactivated strains of lactobacilli in human dendritic cells. Benefic Microbes. 2012;3:91-8.

6. Markowicz C, Kubiak P, Grajek W, Schmidt MT. Inactivation of Lactobacillus rhamnosus $\mathrm{GG}$ by fixation modifies its probiotic properties. Can J Microbiol. 2016;62:72-82.

7. Klaenhammer TR, Kleerebezem M, Kopp MV, Rescigno M. The impact of probiotics and prebiotics on the immune system. Nat Rev Immunol. 2012;12:728-34

8. Derwa Y, Gracie DJ, Hamlin PJ, Ford AC Systematic review with meta-analysis. The efficacy of probiotics in inflammatory bowel disease. Aliment Pharmacol Ther. 2017:46:389-400.

9. Norouzinia M, Chaleshi V, Alizadeh AHM, Zali MR. Biomarkers in inflammatory bowel diseases. Insight into diagnosis, prognosis and treatment. Gastroenterol Hepatol Bed Bench. 2017:10:155-67.

10. Levin AD, Wildenberg ME, van den Brink GR. Mechanism of action of anti-TNF therapy in inflammatory bowel disease. J Crohns Colitis. 2016;10:989-97

11. Vounotrypidis P, Kouklakis G, Anagnostopoulos K, Zezos P, Polychronidis $A$, et al. Interleukin-1 associations in inflammatory bowel disease and the enteropathic seronegative spondylarthritis. Autoimmun Highlights. 2013;4:87-94.

12. Neurath MF. Cytokines in inflammatory bowel disease. Nat Rev Immunol. 2014;14:329-42.

13. Rembacken BJ, Snelling AM, Hawkey PM, Chalmers DM, Axon ATR. Non-pathogenic Escherichia coli versus mesalazine for the treatment of ulcerative colitis. A randomised trial. Lancet. 1999;354:635-9.

14. Vahabnezhad E, Mochon AB, Wozniak LJ, Ziring DA. Lactobacillus bacteremia associated with probiotic use in a pediatric patient with ulcerative colitis. J Clin Gastroenterol. 2013:47:437-9.

15. Salminen MK, Rautelin H, Tynkkynen S, Poussa T, Saxelin M, et al Lactobacillus bacteremia, clinical significance, and patient outcome, with special focus on probiotic L. rhamnosus GG. Clin Infect Dis. 2004;38:62-9.

16. Salvana EM, Frank M. Lactobacillus endocarditis: case report and review of cases reported since 1992. J Infect. 2006;53:e5-10.

17. Besselink MGH, van Santvoort HC, Buskens E, Boermeester MA, van Goor $\mathrm{H}$, et al. Probiotic prophylaxis in predicted severe acute pancreatitis. A randomised, double-blind, placebo-controlled trial. Lancet. 2008;371:651-9

18. Taverniti V, Guglielmetti S. The immunomodulatory properties of probiotic microorganisms beyond their viability (ghost probiotics: proposal of paraprobiotic concept). Genes Nutr. 2011;6:261-74.

19. Sang LX, Chang B, Wang BY, Liu WX, Jiang M. Live and heat-killed probiotic: effects on chronic experimental colitis induced by dextran sulfate sodium (DSS) in rats. Int J Clin Exp Med. 2015;8:20072-8.

20. Fang S-B, Shih $\mathrm{H}-\mathrm{Y}$, Huang $\mathrm{C}-\mathrm{H}$, Li L-T, Chen C-C, et al. Live and heat-killed Lactobacillus rhamnosus GG upregulate gene expression of proinflammatory cytokines in 5-fluorouracil-pretreated Caco-2 cells. Support Care Cancer. 2014;22:1647-54.

21. Imaoka A, Shima T, Kato K, Mizuno S, Uehara T, et al. Antiinflammatory activity of probiotic Bifidobacterium: enhancement of IL-10 production in peripheral blood mononuclear cells from ulcerative colitis patients and inhibition of IL-8 secretion in HT-29 cells. World J Gastroenterol. 2008;14:2511-16.

22. Zhang L, Li N, Caicedo R, Neu J. Alive and dead Lactobacillus rhamnosus GG decrease tumor necrosis factor-alpha-induced interleukin8 production in Caco-2 cells. J Nutr. 2005;135:1752-6.

23. Hwan Choi C, Il Kim T, Kil Lee S, Min Yang K, Ho Kim W. Effect of Lactobacillus GG and conditioned media on IL-1 $\beta$-induced IL-8 production in Caco-2 cells. Scand J Gastroenterol. 2008;43:938-47.
24. Lammers KM, Helwig U, Swennen E, Rizzello F, Venturi A, et al. Effect of probiotic strains on interleukin 8 production by HT29/19A cells. Am J Gastroenterol. 2002;97:1182-6.

25. Wong C, Ustunol Z. Mode of inactivation of probiotic bacteria affects interleukin 6 and interleukin 8 production in human intestinal epithelial-like Caco-2 cells. J Food Prot. 2006;69:2285-8.

26. Enck P, Zimmermann K, Menke G, Klosterhalfen S. Randomized controlled treatment trial of irritable bowel syndrome with a probiotic $E$. coli preparation (DSM17252) compared to placebo. Z Gastroenterol. 2009:47:209-14.

27. Scaldaferri F, Gerardi V, Mangiola F, Lopetuso LR, Pizzoferrato M, et al. Role and mechanisms of action of Escherichia coli Nissle 1917 in the maintenance of remission in ulcerative colitis patients. An update. World J Gastroenterol. 2016:22.5505-11.

28. Wassenaar TM, Zschuttig A, Beimfohr C, Geske T, Auerbach C, et al. Virulence genes in a probiotic $E$. coli product with a recorded long history of safe use. Eur J Microbiol Immunol. 2015:5:81-93. Available from: http://www. ncbi.nlm.nih.gov/pmc/articles/PMC4397850/pdf/EuJMI-05-081.pdf. Accessed 1 August 2016.

29. Kruis W, Fric P, Pokrotnieks J, Lukás M, Fixa B, et al. Maintaining remission of ulcerative colitis with the probiotic Escherichia coli Nissle 1917 is as effective as with standard mesalazine. Gut. 2004;53:1617-23.

30. Wassenaar TM. Insights from 100 Years of Research with Probiotic E. coli. Eur J Microbiol Immunol. 2016;6:147-61.

31. Kataria J, Li N, Wynn JL, Neu J. Probiotic microbes: do they need to be alive to be beneficial. Nutr Rev. 2009;67:546-50.

32. Otte J-M, Podolsky DK. Functional modulation of enterocytes by grampositive and gram-negative microorganisms. Am J Physiol. 2004;286:G613-26.

33. Ren D-Y, Li C, Qin Y-Q, Yin R-L, Du S-W, et al. Lactobacilli reduce chemokine IL-8 production in response to TNF- $\alpha$ and Salmonella challenge of Caco-2 cells. Biomed Res Int. 2013:925219.

34. Shiou S-R, Yu Y, Guo Y, He S-M, Mziray-Andrew CH, et al. Synergistic Protection of Combined Probiotic Conditioned Media against Neonatal Necrotizing Enterocolitis-Like Intestinal Injury. PLOS One. 2013;8:e65108. Available from: http://journals.plos.org/plosone/article/asset?id=10.1371/journal.pone.0065108.PDF.

35. Kuntz S, Kunz C, Rudloff S. Carbonyl compounds methylglyoxal and glyoxal affect interleukin- 8 secretion in intestinal cells by superoxide anion generation and activation of MAPK p38. Mol Nutr Food Res. 2010;54:1458-67.

36. Hill DA, Artis D. Intestinal bacteria and the regulation of immune cell homeostasis. Annu Rev Immunol. 2010;28:623-67.

37. Eckmann L, Kagnoff MF, Fierer J. Epithelial cells secrete the chemokine interleukin-8 in response to bacterial entry. Infect Immun. 1993;61:4569-74.

38. Jung HC, Eckmann L, Yang SK, Panja A, Fierer J, et al. A distinct array of proinflammatory cytokines is expressed in human colon epithelial cells in response to bacterial invasion. J Clin Invest. 1995;95:55-65.

39. Reddy KP, Markowitz JE, Ruchelli ED, Baldassano RN, Brown KA Lamina propria and circulating interleukin- 8 in newly and previously diagnosed pediatric inflammatory bowel disease patients. Dig Dis Sci. 2007;52:365-72.

40. Bai A-P, Ouyang Q, Zhang W, Wang C-H, Li S-F. Probiotics inhibit TNFalpha-induced interleukin-8 secretion of HT29 cells. World J. Gastroenterol. 2004;10:455-7.

41. Ma D, Forsythe P, Bienenstock J. Live Lactobacillus rhamnosus corrected is essential for the inhibitory effect on tumor necrosis factor alpha-induced interleukin-8 expression. Infect Immun. 2004;72:5308-14.

42. Martens U, Enck P, Zieseniss E. Probiotic treatment of irritable bowel syndrome in children. Ger Med Sci. 2010;8:Doc07.

43. Kline KA, Fälker S, Dahlberg S, Normark S, Henriques-Normark B Bacterial adhesins in host-microbe interactions. Cell Host Microbe. 2009;5:580-92. 44. Boyle RJ, Robins-Browne RM, Tang MLK. Probiotic use in clinical practice. What are the risks. Am J Clin Nutr. 2006;83:1256-64; quiz 1446-7.

45. Zargar A, Quan DN, Carter KK, Guo M, Sintim HO, et al. Bacterial secretions of nonpathogenic Escherichia coli elicit inflammatory pathways: a closer investigation of interkingdom signaling. mBio. 2015;6:e00025

46. Guo S, Guo Y, Ergun A, Lu L, Walker WA, et al. Secreted metabolites of Bifidobacterium infantis and Lactobacillus acidophilus protect immature human enterocytes from IL-1beta-induced inflammation: a transcription profiling analysis. PLOS One. 2015;10:e0124549.

47. Bischoff SC, Autenrieth IB. u.a. 1 Aufbau und Funktion der intestinalen Mikrobiota des Menschen. In: Bischoff SC, editor. Probiotika, Präbiotika und Synbiotika. Stuttgart: Georg Thieme Verlag; 2009.

48. Enck P, Zimmermann K, Menke G, Müller-Lissner S, Martens U, et al. A mixture of Escherichia coli (DSM 17252) and Enterococcus faecalis (DSM 16440) for treatment of the irritable bowel syndrome - a randomized controlled trial with primary care physicians. Neurogastroenterol Motil. 2008;20:1103-9. 